\title{
Physical activity in preschool children to fight obesity and related sleep disorders
}

\begin{abstract}
Sleep disorders are frequently associated to obesity, a major public health problem affecting adults as well as a large proportion of children in western countries. Unhealthy lifestyle habits and eating behavior, lack of physical activities are risk factors to develop obesity with consequences on quality of sleep. Despite children enjoy movement; sedentary behavior and lack of environmental opportunities for active play dominate in the preschool child day. Here we discuss the relationship between sleep, physical activity and health, with special interest on obesity. Providing appropriate conditions for children engagement in physical activities is mandatory in western Countries where social organization and cultural tradition limit the opportunities for movement. Improving acquisition of motor competences in children is a must that also involves health professionals as physical activity provides benefits on individual fitness levels and of quality of sleep. In the following pages we will review the links connecting physical activity and obesity with sleep and related disorders. We will then focus on the recent evidences on the determinants of child motor development which provide the scientific rationale for educational interventions promoting quality of health and sleep.
\end{abstract}

Keywords: physical activity, motor skill competence, obesity, sleep, perception of competence
Volume I Issue 2- 2017

\author{
Guido Fumagalli, Patrizia Tortella \\ Department of Diagnostics and Public Health, University of \\ Verona, Italy
}

\begin{abstract}
Correspondence: Guido Fumagalli, Department of Diagnostics and Public Health, Research Center on Child Motor Development, University of Verona, P. le A. Scuro, 10, 37100 Verona, Italy,Tel+390458027605, Email guido.fumagalli@univr.it
\end{abstract}

Received: July 31, 2017| Published: September 18, 2017
Abbreviation: PA, physical activity; MVPA, moderate/ vigorous physical activity; WHO, world health organization

\section{Introduction}

Sleep and physical activity (PA) play critical roles in the metabolic and hormonal systems that drive growth and development in children. ${ }^{1}$ On the other hand, the relationship between these two components of the human behavior is still a controversial issue. ${ }^{2}$ Indeed, contrasting results have been reported depending on age of the subject, ${ }^{3}$ the timing of the activity, ${ }^{4}$ the type of activity performed ${ }^{5}$ and the context. ${ }^{6,7}$ Concerning children, it is not clear the directionality of the relationship between PA and sleep, the quantity of exercise and when it should be practiced to be effective. ${ }^{8}$ Another factor affecting the relationship between sleep and PA is the presence of diseases, ${ }^{2}$ with special emphasis for metabolic disorders and obesity. ${ }^{9}$ Obesity has an impact on the quality of sleep..$^{10}$ Obesity is also a major public health epidemic worldwide with a strong impact on children: it modifies immediate health and quality of life and may lead to early-onset of "metabolic syndrome", which includes hypertension, hyperinsulinemia, hyperlipidemia, type 2 diabetes mellitus, an increased risk of atherosclerosis and cardiovascular diseases. ${ }^{11,12}$ It is estimated that by year 2020 three quarters of all deaths in the developing world will be due to non-communicable diseases related to obesity.

An increasing number of epidemiological evidences suggest a link between sleep duration and obesity in children. A short sleep duration is associated to overweight and obesity, ${ }^{13,14}$ probably by the changes induced by sleep deprivation on the hormonal homeostasis involving leptin, ghrelin, insulin, cortisol and growth hormone. ${ }^{15,16}$ On the other hand, the link between sleep habits and obesity in children still needs further studies; indeed, most of the epidemiological data are based on parent-reported sleep habits with only a few studies using objectively measurements. In a 1 year long longitudinal study examining 111 preschoolers with objective measurements Butte et al. ${ }^{17}$ found not association between sleep duration and weight, On the other hand, fat mass changes occurring during the 1 year of observation were inversely associated with sleep duration; ${ }^{17}$ similar results were reported by a different study. ${ }^{10} \mathrm{~A}$ tighter link is seen between obesity/ adiposity and PA. Moderate/vigorous physical activity (MVPA) seems to be inversely related to adiposity in preschoolers ${ }^{18}$ even though levels of MVPA do not seem to drive the timing of the adiposity rebound. ${ }^{19}$ It is interesting to note that adiposity appears to have an impact on the levels of physical activity in children as levels of PA are inversely related to percentage body fat in preschool children ${ }^{19}$ and fatness in 4 to 5 years old children was associated to low levels of vigorous activity. ${ }^{20}$ On the other hand, the associations between physical activity and adiposity has been questioned ${ }^{18,21}$ and adiposity does not appear to be linked to sedentary behavior. ${ }^{22}$

\section{Discussion}

\section{Promoting motor development}

Because of the links connecting PA with obesity, sleep and health in general, ${ }^{23}$ knowledge of the factor(s) influencing motor behavior will become a priority among health professionals, including those interested in sleep disorders and their correction. Indeed, the World Health Organization (WHO) has developed an integrated package 
of recommendations to address childhood obesity which include promotion of PA for school age children. ${ }^{24}$ The children of most of the Western Countries do not meet the WHO recommendation of physical activity levels. ${ }^{25,26}$ This is particularly negative as motor skill acquisition by practice in early childhood is a fundamental prerequisite for participation in physical activities..$^{27,28}$ Practice leads to competence and motor competences lead to increasing physical activity levels across the life span. ${ }^{29-31}$ In this context, especially relevant for stimulating high levels of MVPA in preschoolers appears to be the acquisition of gross-motor skills. ${ }^{32}$ The physical education guidelines describe motor competence as development of fundamental motor skills such as locomotor (walking, running, jumping, skipping), manipulative (gross and fine skills as throwing, catching and kicking, fine precision object-handling activities) and balance skills (postural stability during body movement). ${ }^{33}$

In developing children, motor skill competences form the foundation of future movement and physically active behavior. ${ }^{34,35}$ Training (and the opportunity of training) provides the fundamental for competence acquisition. ${ }^{32} \mathrm{~A}$ common misconception in that learning movement competences occurs spontaneously (maturation), a misconception that has led to generation of physically illiterate subjects with insufficient levels of fundamental motor skills and poor attitude toward physically active lifestyles. ${ }^{36,37}$ On the contrary, children educated to high levels of motor skill competence in early childhood become very active adults, suggesting the importance of strengthening the development of motor skill competences in early life. ${ }^{38}$ The relationship between development of motor skill competence and physical activity over time is probably mediated by several factors, including perceived motor competence. ${ }^{29,39}$ A positive and negative spiral of engagement or disengagement relates motor competence and physical activity to the risk of obesity, with the mediation of perceived motor competence and health related fitness. ${ }^{29}$ Thus, children with high levels of both motor skill competence and perceived motor skill competence participate more in physical activity, finding it more enjoyable and satisfactory. It is interesting to note that increasing BMI to overweight/ obesity values during childhood growth leads to a decline in motor competence ${ }^{40}$ thus leading to a decline of PA levels and further obesity and low fitness levels. ${ }^{41}$ Providing conditions for learning motor competences and promoting their consolidation is therefore a most important mission for (communities of) educators and governments. In countries, such as Italy, where the school system and the cultural tradition give little emphasis to physical activities and where space for movement is also restricted by an adult-centered social environment promoting development of motor competences is a challenging task. An example of efficient intervention is the playground Primo Sport 0246 located in Trviso, northern Italy, which we have designed to specifically promote gross motor skills in 3-6 y old children. ${ }^{42}$ The published study emphasizes the relevant role played by educators in fostering children motor competences; contrary to old believes on the significance of free-play in building motor expertise in children, the study showed the high impact that activities organized by educators (structured activities) had on increasing gross motor skills. Indeed, a relatively minimal participation to structured activities ( 1 hour repeated 10 times once a week for 10 weeks) caused significant advancements in skills related to manuality and balance. Interestingly, acquisition of these skills had impact on BMI as well (unpublished observation).

\section{Conclusion}

In conclusion, physical activity is required for fitness and wellbeing of children and adults. Lack of adequate levels of activity and sedentary behavior are associated to low quality of life including high occurrence of sleep disorders. Their correction requires specific educational approaches and efforts supporting the growth of fundamental motor skills that should be initiated early during childhood. Do to the impact on quality of health, this knowledge must not be limited to the educational system and the family context; it must also be shared and put in practice by health care professionals, including those interested in the quality of sleep and the correction of the related disorders.

\section{Acknowledgements}

We thank Laboratorio 0246, a private Association located in Treviso, Italy dedicated to the support of children wellness and that generously supports our studies.

\section{Conflict of interest}

The author declares no conflict of interest.

\section{References}

1. Mindell JA, Owens JA, Carskadon MA. Developmental features of sleep. Child Adolesc Psychiatr Clin N Am. 1999;8(4):695-725.

2. Dolezal BA, Neufeld EV, Boland DM, et al. Interrelationship between sleep and exercise: a systematic review. Adv Prev Med. 2017;2017:1-14.

3. Kredlow MA, Capozzoli MC, Hearon BA, et al. The effects of physical activity on sleep: a metanalytic review. J Behav Med. 2015;38(3):427-449.

4. Yasmanaka Y, Hashimoto S, Takasu NN, et al. Morning and evening physical activity and exercise differentially regulate the autonomic nervous system during nocturnal sleep in humans. Am J Physiol Regul Integr Comp Physiol. 2015;309(9):R1112-1121.

5. Alley JR, Mazzocchi JW, Smith CJ, et al. Effects of resistance exercise timing on sleep architecture and nocturnal blood pressure. J Strength Cond Res. 2015;129(5):1378-1385.

6. Nédélec M, Halson S, Abaidia AE, et al. Stress, sleep and recovery in elite soccer: a critical review of the literature. Sports Med. 2015;45(10):13871400.

7. Wennman H, Kronholm E, Partonen T, et al. Physical activity and sleep profiles in Finnish men and women. BMC Public Health. 2014;14:82.

8. Vincent GE, Barnett LM, Lubans DR, et al. Temporal and bidirectional associations between physical activity and sleep in primary school-aged children. Appl Physiol Nutr Metab. 2017;42(3):238-242.

9. Liu J, Hay J, Faught BE. The association of sleep disorders, obesity status and diabetes mellitus among US Adults- The NHANES 2009-2010 survey results. Int J Endocrinol. 2013;2013:234129.

10. Sekine M, Yamagami T, Handa K, et al. A dose-response relationship between short sleeping hours and childhood obesity: results of the Toyama birth cohort study. Child Care Health Dev. 2002;28(2):163-170.

11. Sinaiko AR, Jacobs DR, Steinberger J, et al. Insulin resistance syndrome in childhood: associations of the euglycemic insulin clamp and fasting insulin with fatness and other risk factor. J Pediatr. 2001;139(5):700-707.

12. World Health Organization. The world health report 1997-Conquering suffering, enriching humanity. Geneva, Switzerland: WHO; 1997. 
13. Cappuccio FP, Taggart FM, Kandala NB, et al. Meta-analysis of short sleep duration and obesity in children and adults. Sleep. 2008;31(5):619-626.

14. Kjeldsen JS, Hjorth MR, Andersen R, et al. Short sleep duration and large variability in sleep duration are independently associated with dietary risk factors for obesity in Danish school children. Int $J$ Obes (Lond) 2013;38(1):32-39.

15. Spiegel K, Leproult R, Van Cauter E. Impact of sleep debt on metabolic and endocrine function. Lancet. 1999;354(9188):1435-1439.

16. Spiegel K, Leproult R, L'hermite-Balériaux M, et al. Leptin levels are dependent on sleep duration: relationships with sympathovagal balance, carbohydrate regulation, cortisol and thyrotropin. J Clinal Endocrinol Metab. 2004;89(11):5762-5771.

17. Butte NF, Puyau MR, Wilson TA, et al. Role of physical activity and sleep duration in growth and body composition of preschool-aged children. Obesity (Silver Spring). 2016;24(6):1328-1335.

18. Janz KF, Burns TL, Levy SM. Tracking of activity and sedentary behaviors in childhood: the Iowa bone development study. Am J Prev Med. 2005;29(3):171-178.

19. Sijtsma A, Sauer PJ, Stolk RP, et al. Is directly measured physical activity related to adiposity in preschool children? Int J Pediatr Obes. 2011;6(56):389-400.

20. Janz KF, Levy SM, Burns TL, et al. Fatness, physical activity, and television viewing in children during the adiposity rebound period: the Iowa bone development study. Prev Med. 2002;35(6):563-571.

21. Jiménez-Pavón D, Kelly J, Reilly JJ. Associations between objectively measured habitual physical activity and adiposity in children and adolescents: systematic review. Int J Pediatr Obes. 2010;5(1):3-18.

22. Ekelund U, Hildebrand M, Collings PJ. Physical activity, sedentary time and adiposity during the first two decades of life. Proc Nutr Soc. 2014;73(2):319-329.

23. Timmons BW, Leblanc AG, Carson V, et al. Systematic review of physical activity and health in the early years (aged 0-4 years). Appl Physiol Nutr Metab. 2012;37(4):773-792.

24. WHO. Report of commission on ending childhood obesity. Geneva, Switzerland: WHO; 2016.

25. Guinhouya BC, Samouda H, De Beaufort C. Level of physical activity among children and adolescents in Europe: a review of physical activity assessed objectively by accelerometry. Public Health. 2013;127(4):301311 .

26. Hallal PC, Andersen LB, Bull FC, et al. Global physical activity levels: surveillance progress, pitfalls, and prospects. Lancet. 2012;380(9838):247257.

27. Loprinzi PD, Davis RE, Fu YC. Early motor skill competence as a mediator of a child and adult physical activity. Prev Med Rep. 2015;2:833-838.
28. Sallis JF, Prochaska J, Taylor WC. A review of correlates of physical activity of children and adolescents. Med Sci Sports Exerc. 2000;2(5):963975.

29. Stodden DF, Goodway JD, Langendorfer SJ, et al. A developmental perspective on the role of motor skill competence in physical activity: an emergent relationship. Quest. 2008;60(2):290-306.

30. Lima R, Pfeiffer K, Larsen L, et al. Physical Activity and motor competence present a positive reciprocal longitudinal relationship across childhood and early adolescent. J Phys Act Health. 2017;14(6):440-447.

31. Van Beurden E, Barnett LM, Zask A, et al. Can we skill and activate children through primary school physical education lessons? "Move it Groove it"-a collaborative health promotion intervention. Prev Med. 2003;36(4):493-501.

32. Livonen KS, Sääkslahti AK, Mehtälä A, et al. Relationship between fundamental motor skills and physical activity in 4-year-old preschool children. Percept Mot Skills. 2013;17(2):627-646.

33. Gallahue D, Cleland-Donnelly F. Development Physical Education for All Children. 5th ed. Champain, USA: Human Kinetics; 2017.

34. Clark JE, Metcalfe JS. The mountain of motor development: A metaphor. In: Clark JE, et al, editors. Motor development: Research and reviews. USA: Reston; 2002. p. 163-190.

35. Seefeldt V. Developmental motor patterns: Implications for elementary school physical education. In: Nadeau C, et al, editors. Psychology of motor behavior and sport Human Kinetics. USA: 1980. p. 314-323.

36. Goodway JD, Branta CF. Influence of a motor skill intervention on fundamental motor skill development of disadvantaged preschool children. Res Q Exerc Sport. 2003;74(1):36-46.

37. Goodway JD, Suminski R, Ruiz A. The influence of project SKIP on the motor skill development of young disadvantaged Hispanic children. Res $Q$ Exerc Sport. 2003;74(Suppl):A12.

38. Malina RM. Tracking of physical activity and physical fitness across the lifespan. Res Q Exerc Sport. 1996;67(3 Suppl):S48-57.

39. Robinson LE, Stodden DF, Barnett LM, et al. Motor competence and its effect on positive development trajectories of health. Sports Med. 2015;45(9):1273-1284.

40. Cheng J, East P, Blanco E, et al. Obesity leads to declines in motor skills across childhood. Child Care Health Dev. 2016;42(3):343-350.

41. Duncan M, Bryant E, Stodden D. Low fundamental movement skill proficiency is associated with high BMI and body fatness in girls but not boys aged 6-11 years old. J Sports Sci. 2016;35(21):2135-2141.

42. Tortella P, Haga M, Loras H, et al. Motor skill development in italian preschool children induced by structured activities in a specific playground. PLoS ONE. 2016;11(7):e0160244. 